Agrotrópica 33(2): 109 - 116. 2021.

Centro de Pesquisas do Cacau, Ilhéus, Bahia, Brasil

\title{
ESTUDO DA CLARIFICAÇÃO DO MEL DE CACAU COMO PRÉ-TRATAMENTO PARA PRODUÇÃO DE UMA BEBIDA FERMENTADA
}

\author{
Thalita Gomes de Souza ${ }^{1}$, Bárbara Teodora Andrade Koelher ${ }^{1}$, Soraya Maria Moreira de Souza², \\ Rafael Resende Maldonado (in memoriam) ${ }^{3}$, Elizama Aguiar-Oliveira ${ }^{1, *}$ \\ ${ }^{1}$ Universidade Estadual de Santa Cruz (UESC), Ilhéus, Bahia, Brasil. \\ ${ }^{2}$ Comissão Executiva do Plano da Lavoura Cacaueira (CEPLAC)/ CEPEC, Itabuna, Bahia, Brasil. \\ ${ }^{3}$ Colégio Técnico de Campinas (COTUCA), Universidade Campinas (UNICAMP), Campinas, São Paulo, Brasil. \\ *Autor para correspondência: eaoliveira@uesc.br
}

$\mathrm{O}$ mel de cacau (MC) é uma polpa mucilaginosa, rica em pectina, obtida do fruto do cacaueiro (Theobroma cacao) e apresenta bom potencial para a produção de bebidas alcoólicas, no entanto, faz-se necessário a redução da pectina principalmente para evitar a formação de precipitados. Assim, este estudo teve por objetivo investigar a clarificação do $\mathrm{MC}$, como pré-tratamento, com duas etapas sequenciais: enzimática (pectinases comerciais) e física (bentonita). As melhores condições de clarificação que resultaram nos menores valores de absorbâncias $\left(a b s_{600}=0,055 \pm 0,037\right)$ e densidade $(\rho=1,0547 \pm 0,0012 \mathrm{~g} / \mathrm{mL})$ foram definidas para a etapa enzimática como: 22,57 $\mathrm{U} / \mathrm{mL}$ de poligalacturonase $/ 0,0131 \mathrm{U} / \mathrm{mL}$ de pectinametilesterase $/ 25^{\circ} \mathrm{C} / 75 \mathrm{rpm} / 30 \mathrm{~min}$ e para a etapa física como: $1,0 \mathrm{~g} / \mathrm{mL}$ de bentonita $/ 30 \mathrm{~min} / 4.000 \mathrm{~g}$. Foi ainda investigada a fermentação do $\mathrm{MC}$ clarificado apenas com as pectinases em comparação com o MC in natura e não foi possível identificar diferença significativa entre os teores alcoólicos obtidos $(\sim 8 \%, \mathrm{v} / \mathrm{v})$ após $24 \mathrm{~h}$. Estes resultados sugerem a utilização das pectinases, e também da bentonita, no pré-tratamento do MC para que possa ser destinado à produção de bebidas fermentadas e/ou destiladas.

Palavras-chave: enzimas pectinolíticas, fermentado de fruta, planejamento de experimentos, produtos derivados de frutas.

\section{Study of the clarification of cocoa honey as a pre-treatment for the production} of a fermented beverage. Cocoa honey (MC) is a mucilaginous pulp, rich in pectin, obtained from the fruit of the cacao tree (Theobroma cacao) and has a good potential for the production of alcoholic beverages, however, it is necessary to reduce pectin mainly to avoid the formation of precipitates. Thus, this work aimed to investigate the clarification of $\mathrm{CM}$, as a pre-treatment before fermentation, with two sequential stages: enzymatic (commercial pectinases) and physical (bentonite). The best clarification conditions that favored the lowest absorbance $\left(a b s_{600}=0.055 \pm 0.037\right)$ and density $(\rho=1.0547 \pm 0.0012 \mathrm{~g} / \mathrm{mL})$ were defined for the enzymatic step as: $22.57 \mathrm{U} / \mathrm{mL}$ of polygalacturonase $/ 0.0131 \mathrm{U} / \mathrm{mL}$ of pectinamethylesterase $/ 25^{\circ} \mathrm{C} / 75 \mathrm{rpm} / 30 \mathrm{~min}$ and for the physical step as: $1.0 \mathrm{~g} / \mathrm{mL}$ bentonite $/ 30 \mathrm{~min} / 4,000 \mathrm{~g}$. The fermentation of the clarified MC only with pectinases was also investigated in comparison to the fermentation of $\mathrm{MC}$ in natura and it was not possible to identify a significant difference between the alcoholic levels obtained $(\sim 8 \%, \mathrm{v} / \mathrm{v})$ after $24 \mathrm{~h}$. These results suggest the use of pectinases, and also bentonite, for the pretreatment of $\mathrm{MC}$ so that it can be used in the production of fermented and/or distilled beverages.

Key words: experimental design, fruit products, fruit wine, pectinolytic enzymes. 


\section{Introdução}

O termo "pectina" se refere a um grupo complexo de polissacarídeos estruturais naturalmente encontrado em vegetais (Canteri et al., 2012), no entanto, a suspensão de partículas de pectina (associadas ou não a proteínas, polifenóis, etc.) em sucos e polpas de frutas resulta em uma turbidez e viscosidade indesejadas para processos e produtos industrializados. Os processos de clarificação industrial de sucos e polpas visam a melhoria tanto de características sensoriais quanto tecnológicas, por meio da hidrólise das substâncias pécticas, o que resulta na redução da turbidez e da viscosidade além de prevenir a formação de precipitados que pode acontecer durante as etapas de processamento ou durante o estoque do produto final (Pinelo, Zeuner \& Meyer, 2010; Sandri et al., 2011). Diferentes metodologias podem ser aplicadas para se obter a clarificação de sucos e polpas, mas de forma geral, ela tem sido mais comumente obtida pelo emprego de pectinases (enzimas capazes de hidrolisar as substâncias pécticas) associadas (ou não) a outros agentes físicos como bentonita e alginato (Sainz e Ferri, 2015) ou outras técnicas como a microfiltração (Bagci, 2014). A escolha da metodologia a ser aplicada em diferentes escalas de processo, geralmente é feita em função de fatores como, por exemplo, viabilidade econômica e/ou técnica e a eficiência e compatibilidade com a polpa/suco.

As pectinases podem ser classificadas ${ }^{1}$, a depender da forma como atuam sobre as substâncias pécticas, como: pectato liase (E.C. 4.2.2.2 - atua na ligação $(1,4)$ - $\alpha$-D-galacturonana do pectato), pectina liase (E.C. 4.2.2.10 - atua na posição $(1,4)-\alpha$-Dgalacturonana metil éster da pectina), poligalacturonase (E.C. 3.2.1.15 - hidrolisa de forma randômica as ligações $(1,4)$ - $\alpha$-D-galactosidurônicas de pectato e galacturonanas) e pectina metilesterase (E.C. 3.1.1.11 - hidrolisa a ligação éster entre o ácido galacturônico e o metanol na pectina). Estas enzimas são muito eficientes para a clarificação de sucos e polpas de frutas (Uenojo e Pastore, 2007) e são aplicadas, por exemplo, como soluções (Sandri et al., 2011) ou na forma imobilizada (Ázar et al., 2020).

${ }^{1}$ BRENDA - The Comprehensive Enzyme Information System. Disponível em: https://www.brenda-enzymes.org/ index.php, última consulta em 29/12/2020.
O "mel de cacau" (MC), em comparação com a "polpa de cacau" (PC), é um material mucilaginoso que se encontra mais aderido às sementes do cacau fruto do cacaueiro (Theobroma cacao) - e, devido a seu maior teor de pectina (até cerca de $2,5 \% \mathrm{~m} / \mathrm{v}$ ), apresenta uma maior viscosidade (Santos, 2012). Seu consumo tem sido feito na forma in natura (da mesma forma que a PC) ou empregado, por exemplo, na elaboração de geleias (Santos, 2012) e outros produtos como sorvete (Ramos et al., 2014) e fermentados de frutas (Magalhães-Guedes et al., 2019). O MC também é empregado (artesanalmente) na produção de licores (blend com cachaça), mas apresenta um bom potencial para a produção (em maior escala) de bebidas fermentadas e destiladas. No entanto, se o MC for empregado em etapas como fermentação e/ ou destilação sem a redução do seu conteúdo inicial das substâncias pécticas isso pode resultar na formação de precipitados durante essas etapas.

Assim, tendo em vista a importância da cultura cacaueira na região Sul da Bahia e a necessidade de uma maior variedade de produtos derivados do cacau com maior valor agregado, o presente estudo teve por objetivo investigar as melhores condições para clarificação do MC empregando uma etapa enzimática (com pectinases comerciais) seguida de uma etapa de refinamento com agente clarificante (bentonita). Os resultados obtidos sugerem que, especialmente a clarificação enzimática, pode ser aplicada como etapa de pré-fermentação do MC para a obtenção de bebidas alcoólicas (ou outros produtos).

\section{Material e Métodos}

Mel de cacau (MC) in natura foi adquirido na cidade de Ilhéus (BA, Brasil) entre os meses de setembro a dezembro, em duas safras, em 2018 e 2019. $\mathrm{O} \mathrm{MC}$ foi filtrado com peneira (de uso doméstico) com gaze e pasteurizado a $80{ }^{\circ} \mathrm{C} / 1$ a 2 min em banhomaria e, após resfriamento, foi congelado e assim mantido até o momento de uso. Bentonita, na forma de pó fino, foi doada pela empresa Brasil Minas (Guarulhos, SP, Brasil). As soluções enzimáticas Pectinex ${ }^{\circledR}$ : SMASH XXL (pectina liase de Aspergillus niger), ULTRA SP-L (poligalacturonase de A. aculeatus) e Yieldmash Extra (pectinametilesterase de A. niger) foram doadas pela empresa Novozymes (Araucária, PR) e continham, conforme informações 
do fabricante, atividades de $22.500,3.800$ e 3,30 U/ $\mathrm{mL}$, respectivamente. A solução SMASH XXL também continha atividade residual (valor não declarado) de glicoamilase. A levedura comercial Saccharomyces cerevisiae CA-11, recomendada pelo fabricante para produção de cachaça, foi doada pela empresa LNF (Bento Gonçalves, RS, Brasil).

\section{Clarificação: enzimática e física}

A clarificação de mel de cacau (MC) foi realizada em duas etapas sequenciais, uma enzimática e uma física. Para este fim, foram empregados $50 \mathrm{~mL}$ de MC em Erlenmeyers $(250 \mathrm{~mL})$ sendo adicionado um volume total de $0,5 \mathrm{~mL}$ de soluções de pectinase; a reação foi conduzida em incubadora shaker (MA830 Marconi ${ }^{\circledR}$ ). Em seguida, o agente clarificante bentonita foi adicionado, misturado e após um período de complexação (estática) em temperatura ambiente, o meio foi centrifugado (K14-4000 KASVI) resultando no mel de cacau clarificado (MCC).

O estudo das melhores condições para a clarificação foi conduzido com a ferramenta estatística de planejamento experimental (Rodrigues e Iemma, 2014) sendo aplicada uma matriz do tipo Placket-Burman (PB12) para sete variáveis independentes (fatores) e duas variáveis dependentes (respostas). Para a etapa enzimática, foram investigados os fatores: proporção volumétrica (PEC) do volume total de soluções enzimáticas contendo: pectina liase / poligalacturonase/ pectina metilesterase de 0:3:2 a 4:1:0 (v:v:v), temperatura $\left(T_{\text {pec }}\right)$ de 25 a $55{ }^{\circ} \mathrm{C}$, velocidade de rotação (rpm) de 75 a $125 \mathrm{rpm}$ e tempo de incubação $\left(t_{\text {pec }}, \mathrm{min}\right)$ de 30 a $90 \mathrm{~min}$. Para a etapa física foram investigados os fatores: concentração de bentonina $(C L A)$ de 1 a $4 \mathrm{~g} / \mathrm{L}$, tempo de complexação $\left(t_{c l a}\right)$ de 30 a 90 min e velocidade de centrifugação (cent) de 4.000 a $7.000 \mathrm{~g}$. As respostas avaliadas para o MCC foram: densidade $(\rho, \mathrm{g} / \mathrm{mL})$ e absorbância $\left(a b s_{600}\right)$. A Análises dos Efeitos com $95 \%$ de confiabilidade foi realizada com o auxílio do software estatístico Protimiza Experimental Design ${ }^{2}$ de forma a se selecionar as melhores condições de clarificação.

Com base nas respostas obtidas, duas metodologias de clarificação foram selecionadas: C1 [etapa

${ }^{2}$ Protimiza Experimental Design ${ }^{\circledR}$, disponível em: https:// experimental-design.protimiza.com.br/, último acesso em 15/05/2021. enzimática $=22,57 \mathrm{U} / \mathrm{mL}$ de poligalacturonase $/ 0,0131$ $\mathrm{U} / \mathrm{mL}$ de pectinametilesterase $/ 25^{\circ} \mathrm{C} / 75 \mathrm{rpm} / 30$ min; etapa física $=1,0 \mathrm{~g} / \mathrm{mL}$ de bentonita $/ 30 \mathrm{~min} /$ $4.000 \mathrm{~g}$ ] e $\mathrm{C} 2$ [etapa enzimática $=178,22 \mathrm{U} / \mathrm{mL}$ de pectina liase $/ 7,52 \mathrm{U} / \mathrm{mL}$ de poligalacturonase $/ 55^{\circ} \mathrm{C}$ / $75 \mathrm{rpm} / 30 \mathrm{~min}$; etapa física $=1,0 \mathrm{~g} / \mathrm{mL}$ de bentonita / $30 \mathrm{~min} / 7.000 \mathrm{~g}$ ] e realizadas (triplicata) sendo os valores médios de $a b s_{600}$ e $\rho$ comparados com o MC pelo teste de Tukey (realizado a $95 \%$ de confiabilidade com o Excel ${ }^{\circledR}$, Microsoft).

\section{Fermentação do mel de cacau clarificado (MCC)}

As fermentações foram conduzidas (triplicata) com $50 \mathrm{~mL}$ do $\mathrm{MCC}$ com adição de $0,5 \mathrm{~g}$ (peso seco) da levedura comercial e $5 \mathrm{~g}$ de sacarose para chaptalização; a incubação ocorreu em estufa B.O.D. sob condições estáticas a $29^{\circ} \mathrm{C} / 24 \mathrm{~h}$ (Koelher, 2020). Inicialmente, foram avaliadas as metodologias de clarificação $\mathrm{C} 1$ e $\mathrm{C} 2$ e, ao final das fermentações, os fermentados (F-C1 e F-C2) foram centrifugados a $12.000 \mathrm{~g}$ por $20 \mathrm{~min}$ para separação da massa celular e de outras partículas; o sobrenadante foi analisado quanto a: $a b s_{600}, \rho, S S, \mathrm{pH}$ e teor alcoólico. Em seguida, definiu-se uma nova condição $\mathrm{C} 3$, realizada apenas com a etapa enzimática de $\mathrm{C} 1$ (descrita no item anterior) e procedeu-se a fermentação (F-C3) em comparação com a fermentação do $\mathrm{MC}$; estas duas condições foram analisadas quanto à composição de açúcares, álcoois e ácidos orgânicos.

\section{Análises físico-químicas}

As análises listadas a seguir foram realizadas com base nos protocolos definidos pelo Instituto Adolfo Lutzs (IAL, 2008). A densidade $(\rho, \mathrm{g} / \mathrm{mL})$ foi determinada com picnômetro de $25 \mathrm{~mL}$ (Protocolo 215/ IV). $\mathrm{O} \mathrm{pH}(p H)$ foi determinado com pHmetro de bancada (Protocolo 017/IV) e o teor de sólidos solúveis (SS, ${ }^{\circ}$ Brix) foi obtido com um refratômetro portátil calibrado (Protocolo 010/IV). A presença qualitativa de pectina foi determinada com o teste do álcool (Protocolo 048/IV). A leitura da absorbância $\left(a b s_{600}\right)$ foi realizada no comprimento de onda de $600 \mathrm{~nm}$ (UVVis NOVA $^{\circledR}$ ).

A determinação de sacarose, glicose, frutose, etanol, metanol, ácido lático, ácido acético e ácido cítrico foi realizada por cromatografia líquida em um 
sistema HPLC (Hitachi Primaide) com coluna de troca iônica (Aminex HPX-87H, 300 x 7,8 mm, Bio-Rad) e detector de infra-vermelho (Knauer 98.00). As amostras foram diluídas em água ultrapura e filtradas em membrana PVDF $(0,45 \mu \mathrm{m})$. Foi empregada a fase móvel de $0,005 \mathrm{~N}_{\text {de }} \mathrm{H}_{2} \mathrm{SO}_{4}$ e vazão de $0,6 \mathrm{~mL} / \mathrm{min}$ sendo mantida a temperatura ambiente $\left(\sim 26^{\circ} \mathrm{C}\right) \mathrm{com}$ tempo de corrida de $20 \mathrm{~min}$. A aquisição e integração dos picos foi realizada utilizando o software Star Chromatography Workstation 6.0 (Varian) com base em curvas-padrão previamente obtidas com padrões cromatográficos.

\section{Resultados e Discussões}

\section{Estudo das condições de hidrólise}

$\mathrm{O}$ mel de cacau (MC) in natura, foi inicialmente caracterizado com os seguintes valores: $a b s_{600}=0,722$ $\pm 0,016$ e $\rho=1,0708 \pm 0,0011 \mathrm{~g} / \mathrm{mL}, p H=3,66 \pm 0,08 \mathrm{e}$ $S S=14,40 \pm 2,26^{\circ} \mathrm{Brix}$; os valores de $S S$ e $p H$ foram muito semelhantes aos relatados por Leite et al. (2019). As respostas obtidas com a clarificação realizada em diferentes condições (Tabela 1) foram submetidas a Análise de Efeitos (Tabela 2) para seleção das melhores condições de clarificação que resultassem nos menores valores de absorbância $a b s_{600}$ e $\rho$.
De acordo com a Análise dos Efeitos, para ambas as respostas, a curvatura (condições centrais) não foi estatisticamente significativa (Tabela 2). Isso indica que os valores médios das respostas dos ensaios centrais $(13,14$ e 15$): a b s_{600}=0,046 \pm 0,014$ e $\rho=1,0615 \pm$ $0,0021 \mathrm{~g} / \mathrm{mL}$ (Tabela 1) não representam uma melhora significativa em relação a todos os ensaios realizados que apresentaram valores médios de: $a b s_{600}=0,055 \pm$ 0,004 e $\rho=1,0537 \pm 0,0036 \mathrm{~g} / \mathrm{mL}$ (Tabela 2).

A Análise dos Efeitos para a resposta $a b s_{600}$ apresentou três fatores com efeitos negativos estatisticamente significativos $(p<0,05)$ : a proporção entre as enzimas (PEC), a temperatura de reação enzimática $(T)$ e a centrifugação (cent) (Tabela 2), indicando que seus menores níveis [0:3:2 (v:v:v), 25 ${ }^{\circ} \mathrm{C}$ e $4.000 \mathrm{~g}$, respectivamente] foram favoráveis à clarificação. Entretanto, o menor valor experimental de $a b s_{600}$ - correspondendo a uma redução de 97,8 \% em comparação com o MC - foi obtido com o ensaio 5 (Tabela 1) realizado nos maiores valores de PEC (4:1:0, v:v:v), $T\left(55^{\circ} \mathrm{C}\right)$ e Cent $(7.000 \mathrm{~g})$.

A clarificação de suco de pêssego com solução comercial de poligalacturonase foi realizada por Sainz e Ferri (2015) na temperatura de $50{ }^{\circ} \mathrm{C}$ (valor mais próximo do ensaio 5) já no estudo da clarificação de suco de romã com solução contendo a mesma enzima

Tabela 1 - Matriz codificada Placket-Bruman (PB12) para a clarificação de $50 \mathrm{~mL}$ de mel de cacau com os fatores: proporção volumétrica das soluções de pectinases (PEC, v:v:v), temperatura $(T)$, agitação $(r p m)$, tempo de incubação $\left(t_{\text {pec }}\right.$, min), concentração de bentonita $(C L A, g / L)$, tempo de complexação $\left(t_{c l a}, \min \right)$ e centrifugação $(c e n t, g)$; os valores reais são apresentados entre parênteses. As respostas analisadas foram: absorbância $\left(a b s_{600}\right)$ e densidade $(\rho, \mathrm{g} / \mathrm{mL})$

\begin{tabular}{|c|c|c|c|c|c|c|c|c|c|}
\hline \multirow{2}{*}{ Ensaios } & \multicolumn{7}{|c|}{ Fatores } & \multicolumn{2}{|c|}{ Respostas } \\
\hline & $P E C(v: v: v)$ & $T\left({ }^{\circ} \mathrm{C}\right)$ & rpm & $t_{p e c}(\min )$ & $C L A(g / L)$ & $t_{c l a}(\min )$ & cent $(g)$ & $a b s_{600}$ & $\rho(g / m L)$ \\
\hline 1 & $+1(4: 1: 0)$ & $-1(25)$ & $+1(125)$ & $-1(30)$ & $-1(1,0)$ & $-1(30)$ & $+1(7000)$ & 0,042 & 1,0655 \\
\hline 2 & $+1(4: 1: 0)$ & $+1(55)$ & $-1(75)$ & $+1(90)$ & $-1(1,0)$ & $-1(30)$ & $-1(4000)$ & 0,062 & 1,0666 \\
\hline 3 & $-1(0: 3: 2)$ & $+1(55)$ & $+1(125)$ & $-1(30)$ & $+1(4,0)$ & $-1(30)$ & $-1(4000)$ & 0,087 & 1,0471 \\
\hline 4 & $+1(4: 1: 0)$ & $-1(25)$ & $+1(125)$ & $+1(90)$ & $-1(1,0)$ & $+1(90)$ & $-1(4000)$ & 0,077 & 1,0591 \\
\hline 5 & $+1(4: 1: 0)$ & $+1(55)$ & $-1(75)$ & $+1(90)$ & $+1(4,0)$ & $-1(30)$ & $+1(7000)$ & 0,016 & 1,0443 \\
\hline 6 & $+1(4: 1: 0)$ & $+1(55)$ & $+1(125)$ & $-1(30)$ & $+1(4,0)$ & $+1(90)$ & $-1(4000)$ & 0,026 & 1,0464 \\
\hline 7 & $-1(0: 3: 2)$ & $+1(55)$ & $+1(125)$ & $+1(90)$ & $-1(1,0)$ & $+1(90)$ & $+1(7000)$ & 0,027 & 1,0680 \\
\hline 8 & $-1(0: 3: 2)$ & $-1(25)$ & $+1(125)$ & $+1(90)$ & $+1(4,0)$ & $-1(30)$ & $+1(7000)$ & 0,061 & 1,0485 \\
\hline 9 & $-1(0: 3: 2)$ & $-1(25)$ & $-1(75)$ & $+1(90)$ & $+1(4,0)$ & $+1(90)$ & $-1(4000)$ & 0,106 & 1,0708 \\
\hline 10 & $+1(4: 1: 0)$ & $-1(25)$ & $-1(75)$ & $-1(30)$ & $+1(4,0)$ & $+1(90)$ & $+1(7000)$ & 0,029 & 1,0453 \\
\hline 11 & $-1(0: 3: 2)$ & $+1(55)$ & $-1(75)$ & $-1(30)$ & $-1(1,0)$ & $+1(90)$ & $+1(7000)$ & 0,035 & 1,0522 \\
\hline 12 & $-1(0: 3: 2)$ & $-1(25)$ & $-1(75)$ & $-1(30)$ & $-1(1,0)$ & $-1(30)$ & $-1(4000)$ & 0,090 & 1,0304 \\
\hline 13 & $0(2: 2: 1)$ & $0(40)$ & $0(100)$ & $0(60)$ & $0(2,5)$ & $0(60)$ & $0(5500)$ & 0,039 & 1,0591 \\
\hline 14 & $0(2: 2: 1)$ & $0(40)$ & $0(100)$ & $0(60)$ & $0(2,5)$ & $0(60)$ & $0(5500)$ & 0,036 & 1,0621 \\
\hline 15 & $0(2: 2: 1)$ & $0(40)$ & $0(100)$ & $0(60)$ & $0(2,5)$ & $0(60)$ & $0(5500)$ & 0,062 & 1,0632 \\
\hline
\end{tabular}


Tabela 2 - Análise dos Efeitos para as respostas absorbância $\left(a b s_{600}\right)$ e densidade $(\rho, \mathrm{g} / \mathrm{mL})$ para a clarificação do mel de cacau com os fatores: proporção volumétrica das soluções de pectinases (PEC, v:v:v), temperatura $(T)$, agitação $(r p m)$, tempo de incubação ( $\left.t_{\text {pec }}, \min \right)$, concentração de bentonita $(C L A, g / L)$, tempo de complexação $\left(t_{c l a}\right.$, min) e centrifugação $(c e n t, g)$

\begin{tabular}{l|ccc|rcc}
\hline \multirow{2}{*}{ Termos } & \multicolumn{3}{|c|}{ Resposta: $\boldsymbol{a b s}_{600}$} & \multicolumn{3}{c}{ Resposta: $\boldsymbol{\rho}(\mathrm{g} / \mathbf{m L})$} \\
\cline { 2 - 7 } & Efeito & Erro Pad. & $\boldsymbol{p}$-valor & Efeito & Erro Pad. & $\boldsymbol{p}$-valor \\
\hline Média & 0,055 & 0,004 & $<0,0001^{*}$ & 1,0537 & 0,0036 & $<0,0001^{*}$ \\
Curvatura & $-0,018$ & 0,018 & 0,3439 & 0,0155 & 0,0161 & 0,3721 \\
PEC & $-0,026$ & 0,008 & $0,0182^{*}$ & 0,0017 & 0,0072 & 0,8228 \\
$T$ & $-0,025$ & 0,008 & $0,0192^{*}$ & 0,0008 & 0,0072 & 0,9118 \\
$r p m$ & $-0,003$ & 0,008 & 0,7199 & 0,0042 & 0,0072 & 0,5835 \\
$t_{\text {pec }}$ & 0,007 & 0,008 & 0,4355 & 0,0117 & 0,0072 & 0,1543 \\
CLA & $-0,001$ & 0,008 & 0,8728 & $-0,0066$ & 0,0072 & 0,3967 \\
$t_{\text {cla }}$ & $-0,010$ & 0,008 & 0,2713 & 0,0065 & 0,0072 & 0,3992 \\
Cent & $-0,040$ & 0,008 & $0,0025^{*}$ & 0,0006 & 0,0072 & 0,9404 \\
\hline
\end{tabular}

*Valores estatisticamente significativos com $95 \%$ de confiabilidade $(p<0,05)$. obtenção de um "vinho de fruta", também se mostrou viável, sendo possível observar uma redução de $55 \%$ da viscosidade, outro parâmetro importante para o processamento de polpas e que foi investigado.

Na Figura 1a pode-se observar alguns exemplos da confirmação visual da clarificação em relação a formação de precipitados e a redução da turbidez do meio, já as Figuras 1b e 1c mostram exemplos da realização do teste qualitativo do álcool em que se observa a formação de precipitado que indica a presença de pectina.

Ao comparar os dois ensaios de maior destaque (Tabela 1) - o ensaio 5 (de menor por Cerreti et al. (2017) foi definida a temperatura como $25-30{ }^{\circ} \mathrm{C}$ (mais próximo do valor indicado pela Análise de Efeito - Tabela 2). O emprego de temperaturas mais brandas pode ser muito mais vantajoso para preservar compostos bioativos ou sensoriais das polpas ou sucos, mas é preciso também avaliar em conjunto o desempenho da enzima na temperatura selecionada (Rai et al., 2004).

O menor valor de $\rho(1,0304 \mathrm{~g} / \mathrm{mL})$ foi obtido nas condições do ensaio 12 (Tabela 1) em que todos os fatores se encontravam em seus menores níveis: esse ensaio resultou em reduções de $23,65 \%$ em relação à $\rho$ e $87,5 \%$ em relação a $a b s_{600}$ do MC. Para comparação, o pré-tratamento de polpa de banana com pectinases e á-amilase realizado por Cheirsilp \& Umsakul (2008) antes da etapa de fermentação para $a b s_{600}$ ) e o ensaio 12 (de menor $\rho$ ) - é possível observar que ambos tiveram em comum os menores níveis de rpm e $t_{c l a}$, no entanto, faz-se necessário ressaltar a diferença entre os valores de PEC para estes dois ensaios. Cada uma das pectinases tem características catalíticas próprias e o resultado de suas ações depende também da natureza das substâncias pécticas disponíveis para sua ação. De acordo com as condições experimentais empregadas, a atividade enzimática mais expressiva no ensaio 12 foi a poligalacturonase $(P E C=0: 3: 2, \mathrm{v}: \mathrm{v}: \mathrm{v})$ e no ensaio 5 foi a pectina liase $(P E C=4: 1: 0, \mathrm{v}: \mathrm{v}: \mathrm{v})$ (Tabela 1$)$. Pouco se tem mencionado sobre o uso combinado de diferentes pectinases, sendo muito mais comum o emprego das enzimas isoladamente, sendo a poligalacturonase uma das mais aplicadas, como por

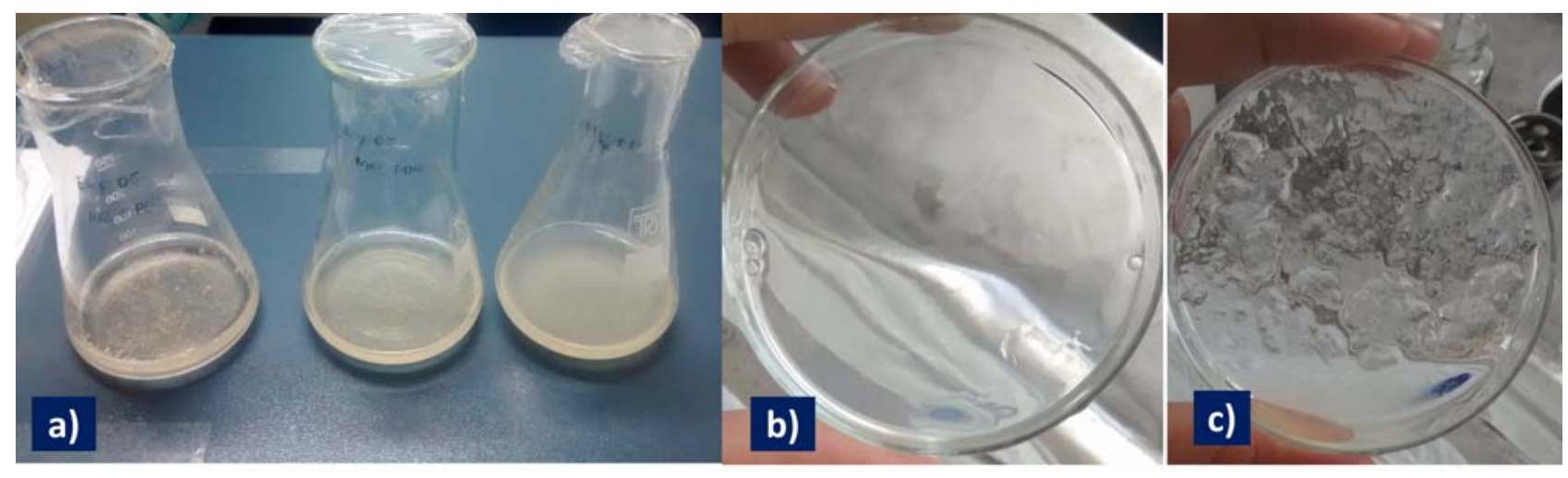

Figura 1 - a) da formação de precipitados e diferentes turbidez apresentadas durante os procedimentos de clarificação e dos resultados do teste qualitativo para pectina b) após e c) antes a clarificação. 
exemplo, nos estudos de: Cerreti et al. (2017), Bagci (2014) e Umsza-Guez et al. (2011). Já a pectina liase foi aplicada por Pinelo, Zeuner \& Meyer (2010) na clarificação de suco de cereja e a pectinametilesterase foi empregada com suco de abacaxi por Patidar et al. (2016) e o estudo de Sandri et al. (2011) avaliou dois extratos contendo diferentes pectinases de A. niger na clarificação de uma solução de pectina.

Desta forma, duas novas condições de clarificação foram selecionadas: a condição $\mathrm{C} 1$ foi realizada nas mesmas condições do ensaio 12 (Tabela 1) - cujas condições estão em acordo com a Análise de Efeitos - e a condição C2 foi baseada no ensaio 5 (Tabela 1) - devido ao menor valor de $a b s_{600}$ - porém, com os valores de $t_{p e c}$ e CLA mantidos iguais aos de $\mathrm{C} 1$.

As repetições destas duas condições de clarificação, $\mathrm{C} 1$ e $\mathrm{C} 2$, apresentaram valores médios de: $a b s_{600}=$ $0,055 \pm 0,037 / \rho=1,0547 \pm 0,0012{\text { e } a b s_{600}}=0,114 \pm$ $0,056 / \rho=1,0660 \pm 0,0053$, respectivamente. Considerando a variabilidade dos experimentos, foi realizado o Teste de Tukey para médias entre as condições: $\mathrm{MC}, \mathrm{C} 1 \mathrm{e} \mathrm{C} 2$. Para a resposta $a b s_{600}$, houve diferença estatisticamente significativa entre MC e os dois tratamentos de clarificação, no entanto, estes tratamentos não apresentaram diferença estatística entre si. De forma complementar, para a resposta $\rho$ não foi identificada diferença estatisticamente significativa entre as três condições analisadas. Dessa forma, e com base na Análise de Efeitos, a condição $\mathrm{C} 1$ foi selecionada como referência para a fermentação.

\section{Fermentação do mel de cacau clarificado}

$\mathrm{O}$ MC foi clarificado pelas metodologias C1 (etapas enzimática e física) e C3 (apenas a etapa por centrifugação. No entanto, é possível ainda inferir que a utilização da bentonita não resulta em um impacto tão significativo quanto a ação das pectinases, sendo assim, é possível sugerir que a clarificação seja realizada apenas com as pectinases.

O desempenho dos fermentados F-C1 e F-C3 após $24 \mathrm{~h}$ foi muito semelhante (Tabela 3), sendo possível observar que o tempo de fermentação poderia ter sido maior de forma a se aumentar tanto a massa celular (para F-C1 foi de 1,04 $\pm 0,16$ g e para F-C3 de 1,23 $\pm 0,20 \mathrm{~g}$, peso úmido) quanto a redução de $S S$ (que foi em torno de apenas $33-34 \%$, Tabela 3 ). Adicionalmente, foram observados acréscimos entre 50 e $87 \%$ dos valores de $a b s_{600}$ após a fermentação (Tabela 3), o que pode ser atribuído, por exemplo, aos açúcares residuais no meio uma vez que a medida no tempo zero equivale ao $\mathrm{MC}$ clarificado antes da chaptalização para preparo do mosto. É possível ainda observar que os fermentados obtidos resultaram em meios mais clarificados (menor $\left.a b s_{600}\right)$ em relação ao MC.

Em seguida, a condição F-C3, foi realizada novamente e as composições obtidas de açúcares, álcoois e ácidos orgânicos foram comparadas em relação à fermentação do $\mathrm{MC}$ (F-MC). De acordo com os resultados apresentados na Tabela 4, e considerando a que não foi detectado metanol em nenhuma das duas amostras e os teores alcoólicos (\%, $\mathrm{v} / \mathrm{v}$ ) foram estimados como $8,8 \pm 0,7 \%$ (F-MC) e 8,2 $\pm 0,8 \%$ (F-C3), é possível observar que as duas condições apresentaram desempenhos semelhantes. Adicionalmente, é possível perceber uma maior composição de glicose e frutose na condição F-C3, o que pode ser entendido como um resultado da hidrólise das substâncias pécticas (Tabela 4). enzimática de $\mathrm{C} 1$ ) e fermentado; a Tabela 3 apresenta os resultados obtidos para $a b s_{600}, \rho, S S$ e $\mathrm{pH}$ antes $(0 \mathrm{~h})$ e após a fermentação $(24 \mathrm{~h})$. As condições iniciais $(0 \mathrm{~h})$ entre $\mathrm{C} 1$ e $\mathrm{C} 3$ sugerem uma melhor clarificação (menor $a b s_{600}$ ) na condição C3 (apenas etapa enzimática). Provavelmente devido a suspensão de partículas muito finas de bentonita no meio que não puderam ser totalmente removidas
Tabela 3 - Valores obtidos para a absorbância $\left(a b s_{600}\right)$, densidade $(\rho, \mathrm{g} / \mathrm{mL})$, teor de sólidos solúveis ( $\left.S S,{ }^{\circ} \mathrm{Brix}\right)$ e $\mathrm{pH}(\mathrm{pH})$ do mel de cacau clarificado com pectinases e bentonita (F-C1) e apenas com pectinases (F-C3) antes ( 0 h) e após $(24$ h) a fermentação com S. cerevisiae CA-11

\begin{tabular}{|c|c|c|c|c|}
\hline \multicolumn{3}{|c|}{$a b s_{600}$} & \multicolumn{2}{|c|}{$\rho(g / m L)$} \\
\hline Fermentado & $\mathbf{0 ~ h}$ & $24 \mathrm{~h}$ & $\mathbf{0 ~ h}$ & $24 \mathrm{~h}$ \\
\hline F-C1 & $0,141 \pm 0,013$ & $0,211 \pm 0,087$ & $1,0627 \pm 0,0032$ & $1,0517 \pm 0,0035$ \\
\hline F-C3 & $0,105 \pm 0,005$ & $0,196 \pm 0,031$ & $1,0567 \pm 0,0072$ & $1,0445 \pm 0,0142$ \\
\hline \multicolumn{3}{|c|}{$S S\left({ }^{\circ} \mathrm{Brix}\right)$} & \multicolumn{2}{|c|}{$p H$} \\
\hline Fermentado & $\mathbf{O} \mathbf{h}$ & $24 \mathrm{~h}$ & $\mathbf{O} \mathbf{h}$ & $24 \mathrm{~h}$ \\
\hline F-C1 & $23,37 \pm 0,90$ & $15,20 \pm 0,92$ & $3,33 \pm 0,01$ & $3,31 \pm 0,01$ \\
\hline F-C3 & $20,80 \pm 1,06$ & $13,87 \pm 3,42$ & $3,44 \pm 0,01$ & $3,35 \pm 0,05$ \\
\hline
\end{tabular}


Tabela 4 - Composição (g/L) de açúcares, glicerol e ácidos orgânicos obtidos após a fermentação $\left(30^{\circ} \mathrm{C} / 24 \mathrm{~h}\right)$ de mel de cacau in natura (F-MC) e clarificado com pectinases (F-C3)

\begin{tabular}{cccccccc}
\hline Fermentado & $\begin{array}{c}\text { Sacarose } \\
(\mathbf{g} / \mathbf{L})\end{array}$ & $\begin{array}{c}\text { Glicose } \\
(\mathbf{g} / \mathbf{L})\end{array}$ & $\begin{array}{c}\text { Frutose } \\
(\mathbf{g} / \mathbf{L})\end{array}$ & $\begin{array}{c}\text { Glicerol } \\
(\mathbf{g} / \mathbf{L})\end{array}$ & $\begin{array}{c}\text { Ácd. Cítrico } \\
(\mathbf{g} / \mathbf{L})\end{array}$ & $\begin{array}{c}\text { Ácd. Acético } \\
(\mathbf{g} / \mathbf{L})\end{array}$ & $\begin{array}{c}\text { Ácd. Láctico } \\
(\mathbf{g} / \mathbf{L})\end{array}$ \\
\hline F-MC & $2,01 \pm 0,04$ & $7,26 \pm 0,53$ & $53,06 \pm 2,74$ & $9,85 \pm 0,76$ & $5,32 \pm 0,23$ & $0,64 \pm 0,07$ & $0,76 \pm 0,07$ \\
F-C3 & $2,16 \pm 0,09$ & $12,21 \pm 1,81$ & $61,70 \pm 2,90$ & $9,63 \pm 0,71$ & $5,24 \pm 0,40$ & $0,67 \pm 0,09$ & $0,95 \pm 0,02$ \\
\hline
\end{tabular}

Fato semelhante, aumento de açúcares solúveis, foi observado na clarificação de polpa de banana por Cheirsilp \& Umsakul (2008). As composições residuais de açúcares (sacarose + glicose + frutose) de ambas as condições analisadas confirmaram mais uma vez que o tempo de fermentação empregado não foi suficiente para resultar em maiores teores alcoólicos, no entanto, a depender da característica desejada para o fermentado, o tempo de fermentação pode ser ajustado. A fermentação de polpa de cacau por $S$. cerevisiae UFLA CA 1162 foi, por exemplo, realizada a $22^{\circ} \mathrm{C}$ e por 30 dias além de cerca de 50 dias de decantação e maturação (Duarte et al., 2010), já a fermentação de mel de cacau por S. cerevisiae AWRI726 foi realizada a $20^{\circ} \mathrm{C}$ por 10 dias (Leite et al., 2019).

A realização apenas da etapa enzimática (como em C3) apresenta a vantagem de simplificação do processo, sendo conhecida a grande eficiência das pectinases. Por exemplo, na fermentação de polpas de cacau por Duarte et al. (2010), foram adicionadas as enzimas poligalacturonase e celulases juntamente com a levedura para promover a fermentação e a clarificação de forma simultânea. Ainda sobre este exemplo, este fermentado resultou em um teor alcoólico $(\sim 8,13 \%$, v/v) muito semelhante ao obtido neste presente trabalho e foram obtidas ainda quantidades menores de glicose $(\sim 3,43 \mathrm{~g} / \mathrm{L})$, de glicerol $(\sim 7,14 \mathrm{~g} / \mathrm{L})$ e de ácido acético $(\sim 0,37 \mathrm{~g} / \mathrm{L})$, ausência de frutose e presença de metanol ( 0,2 g/L) (Duarte et al., 2010). Já a fermentação de mel de cacau por $144 \mathrm{~h}$ resultou em um teor alcoólico maior $(14 \%, \mathrm{v} / \mathrm{v})$ e quantidades maiores de sacarose $(25,34 \mathrm{~g} / \mathrm{L})$ e menores de glicose $(1,35 \mathrm{~g} / \mathrm{L})$ e de frutose $(5,86 \mathrm{~g} / \mathrm{L})$. Em estudo desenvolvido em paralelo em nosso grupo de pesquisa (Koelher, 2020), as condições de fermentação de misturas de mel de cacau e polpa de cacau por S. cerevisiae L63 (boa produtora de pectinase) resultou em teores alcoólicos que variaram de 3 a $14 \%(v / v)$ e absorbâncias em torno de 0,100 .

\section{Conclusões}

Se considerarmos o consumo in natura do mel de cacau (MC), a clarificação pode interferir na aceitação sensorial devido à grande apreciação das suas características naturais (sabor, aroma e aparência), no entanto, para a produção de bebidas fermentadas, o aspecto cristalino tanto do mosto quanto do fermentado é desejado. Assim, a clarificação do MC é proposta neste estudo como técnica coadjuvante (prévia à fermentação) para a produção de bebidas fermentadas (e possivelmente destiladas) de forma a se obter produtos com maior valor agregado. De acordo com o estudo realizado, foi possível definir a clarificação do $\mathrm{MC}$ com pectinases comerciais (poligalacturonase $\mathrm{e}$ pectinametilesterase) e, opcionalmente, com uma etapa física sequencial empregando o agente clarificante bentonita. Os resultados obtidos (especialmente em relação à redução da absorbância) indicaram que a clarificação do MC é possível de ser obtida devido à redução do conteúdo das substâncias pécticas promovido em grande parte pela ação das pectinases. Assim, o emprego de pectinases é válido devido a sua eficiência e disponibilidade comercial atual, o que pode ser levado em consideração em diferentes escalas de produção de derivados do $\mathrm{MC}$, quando aplicável.

\section{Agradecimentos}

Os autores são gratos pelo apoio financeiro do Conselho Nacional de Desenvolvimento Científico e Tecnológico (CNPq) - Processo: 425959/2018-0 - e pelo inestimável apoio experimental do Laboratório de Microbiologia Aplicada da Agroindústria (LABMA, UESC).

\section{Literatura Citada}

ÁZAR, R. I. S. L. et al. 2020. Apple juice clarification by a purified polygalacturonase from Calonectria pteridis. Food and Bioproducts Processing 119:238-245. 
BAGCI, P. O. 2014. Effective clarification of pomegranate juice: A comparative study of pretreatment methods and their influence on ultrafiltration flux. Journal of Food Engineering 141:58-64.

CANTERI, M. H. G. et al. 2012. Pectina: da matériaprima ao produto final. Polímeros 22(2):149-157.

CERRETI, M. et al. 2017. Optimization of pectinase and protease clarification treatment of pomegranate juice. LWT - Food Science and Technology 82:58-65.

CHEIRSILP, B.; K. UMSAKUL, K. 2008. Processing of banan-based wine product using pectinase and á amylase. Journal of Food Process Engineering 31(1):78-90.

DUARTE, W. F. et al. 2010. Characterization of different fruit wines made from cacao, cupuassu, gabiroba, jaboticaba and umbu. LWT - Food Science and Technology 43(10):1564-1572.

INSTITUTO ADOLFO LUTZ - IAL. 1991. Métodos físico químicos para análise de alimentos. $4^{\mathrm{a}} \mathrm{ed}$. Coordenadores: Odair Zenebon, Neus Sadocco Pascuet e Paulo Tiglea, São Paulo, SP, Instituto Adolfo Lutz. 1020p.

KOELHER, B. T. A. 2020. Avaliação da aplicabilidade de cepas Saccharomyces cerevisiae na produção de bebidas alcoólicas utilizando mel e polpa de cacau como substrato. Dissertação de Mestrado. Ilhéus, Bahia. Universidade Estadual de Santa Cruz (UESC). 80p.

LEITE, P. B. et al. 2019. Cocoa's Residual Honey: Physicochemical Characterization and Potential as a Fermentative Substrate by Saccharomyces cerevisiae AWRI726. The Scientific World Journal 5698089.

MAGALHÃES-GUEDES, K. T. et al. Bebida alcoólica de mel de cacau fermentada por levedura Saccharomyces cerevisiae: Tecnologia de aproveitamento de resíduo alimentício. In: Inovação em Ciência e Tecnologia de Alimentos. V. B. Viera e N. Piovesan (eds). São Paulo, Atena. pp.37-45.
PATIDAR, M. K. et al. 2016. Papaya peel valorization for production of acidic pectin methylesterase by Aspergillus tubingensis and its application for fruit juice clarification. Biocatalysis and Agricultural Biotechnology 6:58-67.

PINELO, M.; ZEUNER, B.; MEYER, A. S. 2010. Juice clarification by protease and pectinase treatments indicates new roles of pectin and protein in cherry juice turbidity. Food and Bioproducts Processing 88(2-3):259-265.

RAI, P.; MAJUMDAR, G. C.; DASGUPTA, S.; DE, S. 2004. Optimizing pectinase usage in pretreatment of mosambi juice for clarification by response surface methodology. Journal of Food Engineering 64(3):397-403.

RAMOS, D. C. et al. 2014. Composições Alimentícias de Chocolate e de Gelado Comestível Contendo Mel de Cacau. Patente BR 102013 005053-9 A2.

RODRIGUES, M. I.; IEMMA, A. F. 2014. Planejamento de experimentos e otimização de processos: uma estratégia seqüêncial de planejamentos. $3^{\mathrm{a}}$ ed. Campinas, SP, Editora Casa do Pão. xp.

SAINZ, R. L.; FERRI, V. C. 2015. Vida-de-prateleira de sucos clarificados de pêssegos das variedades jubileu e eldorado. Brazilian Journal of Food Technology 18(3):239-249.

SANDRI, I. G. et al. 2011. Clarification of fruit juices by fungal pectinases. LWT - Food Science and Technology 44(10):2217-2222.

SANTOS, C. O. 2012. Aproveitamento industrial de "mel" de cacau (Theobroma cacao L.) na produção de geléia sem adição de açúcar. Dissertação de Mestrado. Salvador, Bahia, Universidade Federal da Bahia (UFBA). 92p.

UENOJO, M.; PASTORES, G. M. 2007. Pectinases: aplicações industriais e perspectivas. Química Nova 30(2):388-394.

UMSZA-GUEZ, M. A. et al. 2011. Effect of pectinolitic enzymes on the physical properties of caja-manga (Spondias cytherea Sonn.) pulp. Ciência e Tecnologia de Alimentos 31(2):517-526. 